\title{
Reimagining health and fitness materials: an affective inquiry into collaging
}

Carrie Safron, Teachers College, Columbia University, Department of Biobehavioral Sciences e-mail cjs2172@tc.columbia.edu twitter@cjs2172

\section{Abstract}

This paper, or 'experiment,' draws on data from a health and fitness scrapbooking project with four Black and Latinx youth. While the data are part of a longer 18-month visual ethnography (Pink, 2013), the focus here began to consider one week of the project in which the four youth and I interacted with health and fitness related magazines. In that week, we created magazine re-assemblages in our scrapbooks. To reimagine what 'matters' for education research and pedagogical practices in health, fitness and physical culture, I re-visited data (Levy, Halse \& Wright, 2016) through an affective lens (Deleuze \& Guattari, 1987), drawing on PhEmaterialism (Ringrose, Warfield \& Zarbadi, 2019). The affective lens produced a collage inquiry entangled with doubt (Holbrook \& Pourchier, 2014), wonder (MacLure, 2013a) and slowness (Renold, 2018), which began to open up possibilities to think-see-feel my way through the data and the process differently.

Keywords: collage as inquiry, affect, young people, scrapbooking, health and fitness 


\section{A 'prologue'}

First, a confession. What I think, feel, work and write through in this paper is truly an 'experiment.' It represents an assemblage ${ }^{1}$ of data generated (Tinning \& Fitzpatrick, 2012) from my doctoral dissertation. This dissertation, an 18-month visual ethnography (Pink, 2013) with Black and Latinx youth in an urban after-school program in the Northeast Region of the United States (U.S.), aimed to explore health and fitness across pedagogical sites (e.g., magazines, internet, commercial gyms) (Tinning, 2010). In the spirit of confession, I must admit, when I began this research, I cast the net wide (Bogdan \& Biklen, 2007; Emerson, Fretz, \& Shaw, 2011). I did not have experience working with high-school aged teenagers, the age of the youth who became my participants. I was not trained as a researcher or teacher. My background was as a personal trainer, with degrees in Nutrition and Applied Exercise Physiology. I was a 30-something year-old White woman from a privileged suburban upbringing 'inserting' myself into an urban after-school program, attended predominantly by young people of color from a lower socioeconomic background. Given this, my approach to this dissertation was affected by normative assumptions and understandings of the research assemblage.

My understanding of qualitative research was (loosely) based in post-positivist and constructivist epistemologies, involving a sense of linearity from data collection to analysis to writing and representation. Yet, as I spent time in the research context (after-school site), built relationships with youth, and engaged with various methods (participant observation, visual diaries, scrapbooking), "the traditional linear 'process' trajectory" (St. Pierre \& Jackson, 2014, p. 717) felt lacking - fell short. The coding and categorizing of an 'inductive' and 'deductive' analysis (Creswell, 2013) might have (at first) opened little tidbits from participants' engagement with visual methods, but it also reproduced normative knowledge(s) and themes around health, fitness and youth (see Levy, Halse, \& Wright, 2016). From this point, I felt I needed something different and took a divergent path - perhaps a line of flight (Deleuze \& Guattari, 1987). As I will discuss, I turned to theoretically informed methods to disrupt reproductive research processes within health, fitness and physical education (PE). I began to re-visit data from my dissertation by drawing on such theories and methods. The purpose of this paper, therefore, is to (re-)present (Allen, 2011) the theoretical-methodological processes undertaken in my dissertation through an affective lens, within a broader PhEmaterialist perspective.

\footnotetext{
${ }^{1}$ Assemblages are heterogeneous arrangements of material and non-material elements (e.g., objects, bodies, expressions, qualities, knowledge, culture) that develop "in different ways at different times to produce a particular activity" (Strom, 2015, p. 2). The term assemblage is used in this paper to refer to various parts that come together and apart throughout the (research) process. For instance, the research assemblage includes components of the research (participants, researcher, scrapbooks, transcripts, context) that are grouped together through particular moments (Fox \& Alldred, 2017).
}

Reconceptualizing Educational Research Methodology 2019, 2,3(2) Special Issue https://journals.hioa.no/index.php/rerm/issue/view/397 


\section{PhEmaterialism: an affective process}

I know I have yet to offer a background on the research (and concomitant data) that I write about here. That will come. I do this somewhat purposefully as one of the strengths in what has been termed PhEmaterialism is its ability to offer differing entry points into the research process, from thinking to doing to (re-)presenting in diverse ways (Ringrose, Warfield, \& Zarabadi, 2019). So, I think of this paper (or 'experiment') as an entangled memo that infinitely unfolds and refolds over time. PhEmaterialism, an assemblage itself of posthumanism, multiple feminisms and (new) materialism, strives to re-mix and re-imagine "habitual relationalities..." to move "educational research somewhere different than before" (Ringrose et al., 2019, p. 1). In other words, PhEmaterialism entangles multiple theories (and methods) to generate "new ways of doing" (ibid, p. 1) while simultaneously slowing down and reconfiguring what counts as research engagement (Renold, 2018). It offers the world as nonlinear, complex and shifting and, in doing so, activates all bodies (humans, materials, emotions, thoughts) to be productive (Niccolini, Zarabadi, \& Ringrose, 2018).

While PhEmaterialism is composed of multiple theories (Ringrose et al., 2019), one in particular came to matter in this research - affect (Deleuze \& Guattari, 1987; Hickey-Moody, 2013; Niccolini et al., 2018). As I wrote in the 'prologue,' I did not begin this doctoral dissertation with an affective lens. Yet, as I spent more time in the research site (urban after-school context), engaged further with participants, generated multiple forms of data (interviews, visual diaries, scrapbooks), transcribed the interviews/group sessions myself, and pored over data again and again, a multitude of sensations surfaced. For instance, moments within the data emerged which I could not escape (Safron, 2019). I discovered this to be wonder - hot-spots or glows - radiating "in the entangled relation of data-andresearcher" (MacLure, 2013a, p. 228). In this wonder, I began to feel-think-sense the importance of all bodies (images, scrapbooks, texts, participants, researcher, thoughts) entangled simultaneously. One could not be separated from the other. One did not begin as more or less significant than the other. Rather, bodies picked up intensities or slowed down through their ongoing connections. The varying collectivity of human and non-human bodies, which come together (and apart) in different ways and times, through various speeds and directions, represent an assemblage (Strom, 2015). The intensities that augment or diminish capacities of assemblages are affect (Fox \& Alldred, 2017). In reimagining what 'matters' in educational research, pedagogical and political practice, affect began to invade and consume movements within (and between) the data inquiry in this paper.

Seigworth and Gregg (2010) wrote in their introduction to The Affect Theory Reader, "There is no single, generalizable theory of affect" (p. 3) and, thus, I do not stick to a clear 'definition' as I work with affect (and affect works on me) throughout this 'experiment.' Still, I would be remiss if I did not mention how I came to think-work with affect in the instance of this paper. First, I drew on Deleuze and Guattari (1987) and Massumi's translation of affect:

Reconceptualizing Educational Research Methodology 2019, 2,3(2) Special Issue https://journals.hioa.no/index.php/rerm/issue/view/397 
It is a prepersonal intensity corresponding to the passage from one experiential state of the body to another and implying an augmentation or diminution in that body's capacity to act (p. xvi).

This translation pulled at me because it represents the relational, unknowing capacity of affect and what affect may do. Affect is not a characteristic; it is not personal, is not the same as feeling or emotion and is not a singular independent thing. It is the "body's capacity to act" (p. xvi) and bodies consist of human and non-human elements. Drawing on Deleuze and Guattari, Hickey-Moody (2013), wrote "affect is what moves us. It's a hunch. A visceral prompt" and "a starting place from which we can develop methods that have an awareness of the politics of aesthetics" (p. 79). For MacLure (2013a), affect is represented through wonder and this wonder is not necessarily positive, safe or entirely under our control:

Wonder is relational. It is not clear where it originates and to whom it belongs. It seems to be "out there," emanating from a particular object, image, or fragment of text; but it is also "in" the person that is affected. A passion: the capacity to affect and to be affected (p. 229).

Thus, in these instances, affect pops up through the unexpected (wonder, hunch) and becomes attached to a multitude of sensations (visceral, uncomfortable) and aesthetic processes. In this paper, I tried to work with-through affect by opening the data (and myself) to wonder.

Second, in drawing on the affective turn within feminist theory, Fullagar and Pavlidis (2018) explain that affect, through material, visceral and discursive dimensions, can engage complexities around gender and power in sport. Through the example of roller derby and Jen, the scholars illuminate how "power relations work through a range of affects and contexts" (p. 454). In taking up roller derby after her mothers' death, Fullagar and Pavlidis (2018) explicate how Jen's 'feelings' do not exist on their own but are entwined with grief, love, support, friendship and experience. Affect, then, is not determined in advance; it is continuously altered and re-made through relations between bodies. I resonated with this narrative because, in this paper, the young participants, their subjectivities, scrapbooks, texts and a variety of other materials altered and re-made the research (and continually alter me).

Recognizing the importance of context, Fullagar and Pavlidis (2018) also explain that affects are entangled in historical, economic, and political conditions. These entanglements are heavily present (and affective) in sport, fitness and PE environments. For example, over 35 years ago, Nancy Theberge (1981) argued that sport was "a fundamentally sexist institution that is male dominated and masculine oriented" (p. 342). This is not to say that sport was developed with an explicit aim to assert masculine dominance over feminine subjects. Rather, sport (along with health, fitness and PE) manifests in relation to larger networks of historical, political and economic assemblages that affect its organizational structures (Pringle, 2007). Body-focused sites in sport, health, fitness and media work to assert gender, 
race and class differences (Fitzpatrick, 2013) that are part of broader socio-material assemblages. Traditional qualitative research methods have, reproduced similar outcomes as part of these broader assemblages. For instance, in PE, Azzarito (2009) proffered that youth narrowly depict the ideal body as slender for women, athletic and muscular for men, and often White. The beginning of my dissertation led to similar results; a linear qualitative stance reproduced the binary notions (fit/fat, normal/abnormal) that I was looking to disrupt. Then, in turning to affect (and PhEmaterialism more broadly), data became intensities that augmented my ability to reimagine and produce new (reIpresentations of health, fitness and the body. I drew inspiration from current approaches in the fields of health, fitness and PE to do so.

\section{Links to health, fitness and physical education}

I began to discover part of the 'problem' in health, fitness and PE fields, like other areas in education (Strom, 2015), is that research continues to be centered on outcomes over process. In other words, because of an alignment with biomedicine (Johns \& Tinning, 2006) and strong ties with public health organizations (e.g., Cooper Institute, Physical Activity Guidelines for Americans), corporations (e.g., National Football League, Nestlé) and/or fitness testing regimens (e.g., Fitnessgram ${ }^{\circledR}$ ), research on youth (and their bodies) has been narrowed to standardized approaches that aim to achieve predetermined health, fitness or performance outcomes (Gard \& Pluim, 2017). In broader physical culture (sport, leisure, health, fitness, exercise), research has also been "governed by a range of normative assumptions...to simplify the complex experiences and profound inequities inscribed through the social order" (Fullagar, 2017, p. 248). As such, from PE (Azzarito, 2009; Fitzpatrick, 2013) to sites of physical culture (Coffey, 2017), health and fitness are entwined with social, cultural and economic factors that prioritize gendered, classed, and racialized norms (e.g., feminized White, young, able-bodied ideals of beauty) (Fullagar \& Pavlidis, 2018). Like Fullagar (2017), I argue it is important to engage in ways that critique, reimagine and change these established norms.

Notably, recent scholarship in PE (Landi, 2019), sport (Fullagar \& Pavlidis, 2018), health and fitness (Coffey, 2017; Lupton, 2018; Markula, 2008) has drawn on new materialist, feminist and post-humanist theoretical and methodological processes. Landi (2019) used new materialist concepts of affect and assemblage in a critical ethnography with queer men in New Zealand, arguing that PE (as a field) plays an active role in the production of queer bodies and desire, and that this desire can be transformative. Using a feminist new materialist framework, Lupton (2018) examined young Australians' engagement with health and fitness through digital and non-digital sources. She proffered that a feminist new materialist framework allowed "entanglements of technological and fleshy human affordances" to be considered, demonstrating the relational capacities between human and non-human bodies (ibid., p. 11). Coffey (2017) explored gendered dimensions of body work practices (muscle-building and cosmetic surgery), employing concepts of assemblage, becoming and affect to highlight that bodies are processes,

Reconceptualizing Educational Research Methodology 2019, 2,3(2) Special Issue

https://journals.hioa.no/index.php/rerm/issue/view/397 
constantly shifting based on relations in the world. Levy, Halse and Wright (2016) utilized data from their previous work with preteen boys and girls diagnosed with eating disorders to explore what shifting from a feminist post-structuralist framework to feminist post-humanist thinking might produce. Thus, even amidst a lack of critical scholarship, especially in the U.S. (Fitzpatrick, 2018; Gard \& Pluim, 2017), there are opportunities "to open up a discursive space to converse...and invite people to engage at different points from different perspectives" (Fullagar, 2017, p. 255). This is where (and how) this 'experiment' (paper) begins. It is a (re-)presentation of the approaches I used to challenge normative (dis-embodied) modes of inquiry during my dissertation.

\section{What does this paper do?}

Back to confession. Even though, as I wrote this paper (and pored over data generated), I have 'left' the research site, these openings from recent PE and physical culture scholarship brought a chance to revisit and re-think data from my dissertation. By re-visiting data from my dissertation, I reimagined what an affective lens (incorporating principles of PhEmaterialism) might offer in exploring relations between all bodies. Parts of the data (and the process) kept nagging at me and could not be captured through traditional qualitative approaches. As this nagging continued, I was drawn to affect (Deleuze \& Guattari, 1987); these were the sensations, intensities and forces of everyday life that began to (unexpectedly) manifest in relations between human (researcher, participants) and non-human (materials, knowledge, culture) bodies, in turn, producing further affects (or potential openings and/or closings).

Through such re-visiting and re-thinking (Levy et al., 2016), this paper began to draw on one week of a scrapbooking project that was part of the 18-month visual ethnography. During this week, four Black and Latinx youth and I interacted with health and fitness related magazines, knowledge(s) and materials. Thus, in reimagining what 'matters' through an affective lens, this paper became an 'experiment' - an unforeseen inquiry into collaging that arose from wonder (MacLure, 2013a), doubt (Holbrook \& Pourchier, 2014), and slowness (Renold, 2018). This wonder, doubt and slowness were themselves produced through the affective potential of a magazine re-assembling, which I will discuss after a brief background on the project itself.

\section{A (brief) background: the research and visual ethnography}

As this was part of my doctoral dissertation, I was faced with certain expectations about the research process. For example, I entered the site with an approved IRB from my university institution and a plan based on previous scholarship and coursework. The after-school context was chosen because of the variety of health and fitness-related activities (e.g., weight room, boxing, step/dance, basketball) offered within a larger program. I began by spending most of my time in the weight room, getting to know young people who came in, asking and answering questions, and even working out with youth in this project. In establishing connections with young people (whom I met in and out of the weight room), we 
began to experiment with different approaches (semi-structured interviews, visual diaries, special events with fitness professionals) to see what stuck. Pink (2013) described visual ethnography as a "process of continuous innovation" (p. 34), or perhaps a process of becoming (Deleuze \& Guattari, 1987). This became an appropriate reminder in the after-school context.

Through this flexible "process of learning and experiencing" (Pink, 2013, p. 31) with youth in the afterschool context, my theoretical-methodological perspective changed. Data were no longer pieces of static information - out there - waiting to be collected and reported; data were generated (Tinning \& Fitzpatrick, 2012) from the relations and subjectivities entangled and produced between myself, youth and materials in this context. Learning from young people attending the after-school program affected the research. It took much time and care to reach a place in which the young participants and I came to collaborate. This ongoing involvement eventually led to a nine-week scrapbooking project (at the end of the visual ethnography) in which four Black and Latinx youth ( 3 girls, 1 boy) and I came together to explore pedagogical sites (e.g., print magazines, internet, commercial gyms) of health and fitness.

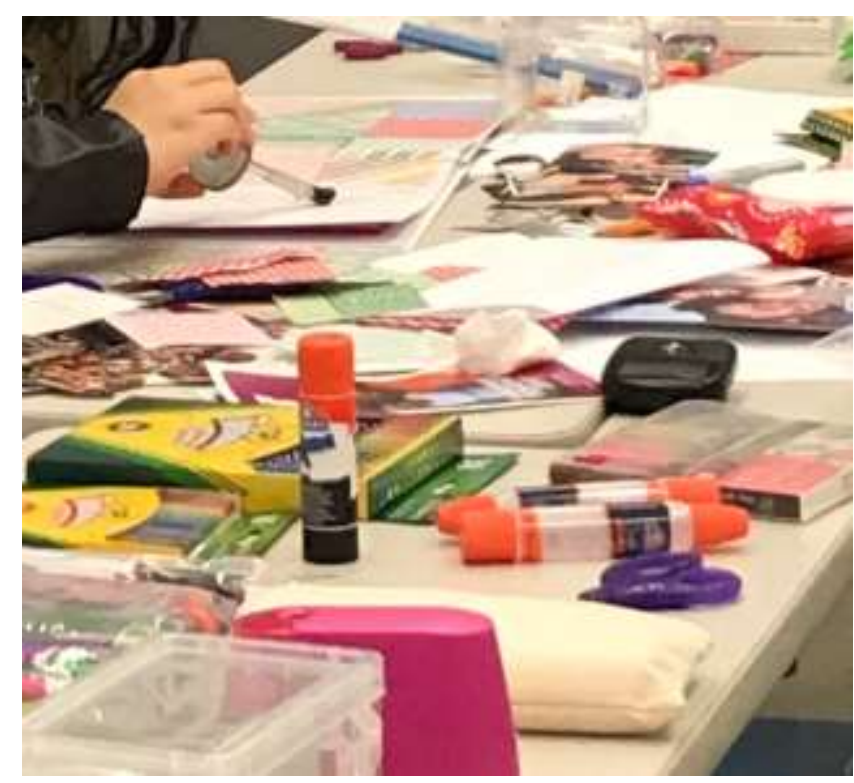

Figure 1. Materials used to create scrapbook assemblages.

Each week, during the scrapbooking project (Bragg \& Buckingham, 2008; Enright \& O'Sullivan, 2013), the four participants and I met in a room at the after-school site for 60 to 90-minutes. Importantly, my mother is a former art teacher (of 35 years) and equipped me with boxes of materials, including various types of glue, markers, colored pencils, stickers, stamps, patterned and solid construction paper, and more (figure 1). Through these materials, as well as others (e.g., participant and researcher-driven images, magazines) that were included, we immersed ourselves in exploration, conversation and 
critique, creating assemblages through the affective materiality produced in the scrapbooking process. The data I draw on in this paper emerged from the third week of the scrapbooking project. In this week, the four young participants and I embarked on an 'affective journey' (Niccolini, 2016b) into print media, examining health and fitness related magazines. This journey also came to (re-)present the affective inquiry, an entanglement of theory, methods and 'findings,' that is explored next.

\section{An affective inquiry}

Levy, Halse and Wright (2016) explained that a re-thinking and re-searching of their methodological and epistemological orientations produced "different ways in which doors opened and closed" (p. 185). Taking a cue from them, along with arguments for post-humanist material processes in physical culture research (Fullagar, 2017; Markula, 2019), affect provided an opening. Coding and categorizing did not 'fit' with the creative process of scrapbooking and magazine re-assemblages ${ }^{2}$ produced by the young participants. Alternative (methodological-theoretical) approaches began to affect thinking and doing. In this, the inquiry might be considered somewhat of an unpredictable mess. I drew from various techniques (e.g., wonder, collaging, doubt, slowness, writing, video making), often not knowing where one ended and another began. Yet, continuing the confession, I do want to offer some insight into how this 'experiment' with/through affect emerged and what affective capacities the inquiry produced. In the sections below, I explain the non-linear process that began to emerge.

\section{The health and fitness magazine re-assemblage}

I brought in a selection of health and fitness related magazines on the third week of the scrapbooking project, displaying them on one of several tables in our meeting room. We began with some general catch-up (conversation about our week), discussion of the previous session, and a little brainstorming on what fitness and health means to each of us (figure 2). Then, we turned our focus to the magazines. Guidelines, as with each week, were open-ended. As researcher-facilitator-participant, I typically offered some critical questions or a prompt as a 'starting' point. This week, the prompt was 'use the magazines (and other materials) to tell any story you would like to about fitness and health.' We then used this prompt to pull apart and re-assemble materials into our own scrapbooks - creating a re-assemblage.

\footnotetext{
${ }^{2}$ Magazine re-assemblages here refer to the process and 'products' re-assembled in producing collages during week three of the scrapbooking project. On this week, the participants and I used health and fitness magazines and other materials to produce 'new' assemblages (or re-assemblages). Later, in this inquiry, I re-assemble these magazine re-assemblages.
} 


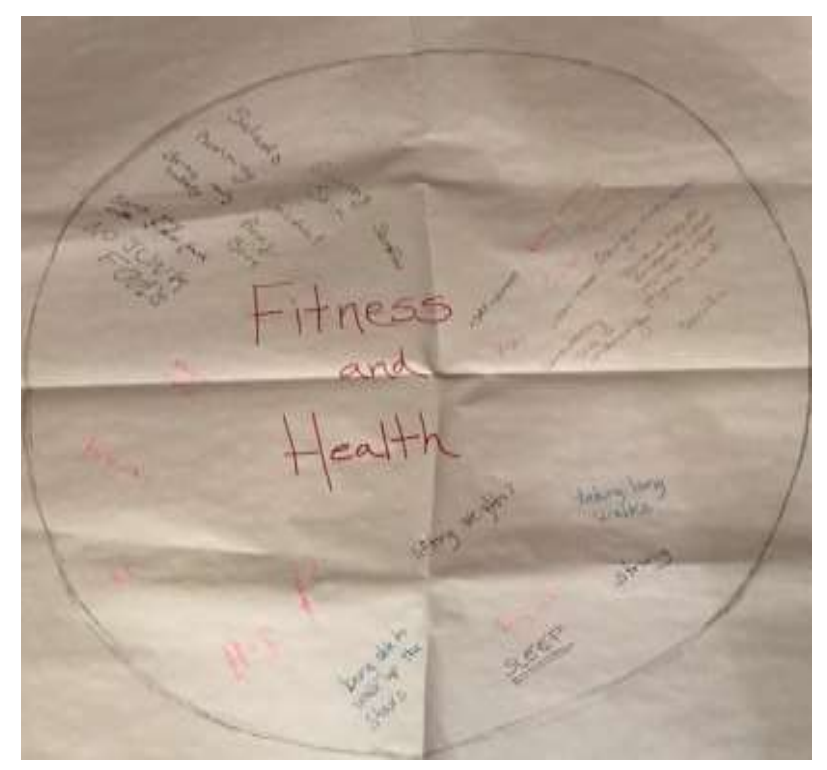

Figure 2: Quick brainstorming on health and fitness.

The start of each scrapbooking session was not always seamless. Initial moments (sharing snacks, catching up on conversations, checking phones, commenting on social media, off the cuff gossip) noisily filled the air and took precedence. The school day had ended, and this was the place to let loose. Sara moved the magazines to the table at which we sat. Even though we had plenty of tables, chairs, and space, we often ended up sitting close to each other - surrounded by the materials - at one section of a long table. As eating slowed, chatter grew louder. Sara, who was leafing through the magazines, commented on recipes - 'a mocha black bean cake with cashew cream. I've never heard of that!' Alicea sat next to me, pulling at her large gold hoop earring, sighing - 'they're making me tired.' When I suggested she take them off, she responded in astonishment - 'I feel naked without earrings. Like naked.' There was discussion around the best technique for rubber cement glue. Then, we began to find some rhythm, interspersing conversation, eating, and making. Construction paper, colored markers and pencils, glue, scissors, and other materials - spread out and covered the table. We ripped pages out of magazines. We cut out advertisements, articles, images and advice columns. Discarded elements fell to the floor. We commented on what we saw. Sara - 'It's like this is what you have to look at to be considered healthy and beautiful and then when you realize you're not like that, it's like oh...' Keenan 'Oof, yeah.' We glued snippets from the magazines we had ripped and cut into our scrapbooks. We intertwined these snippets with different ideas and things - words, drawings, construction paper, layering over and under. Blank pages in our scrapbooks were now covered with a re-mix of materials, colors, words, feelings, and illustrations. These health and fitness magazines, which began as assemblages themselves, became re-assembled (figure 3). 


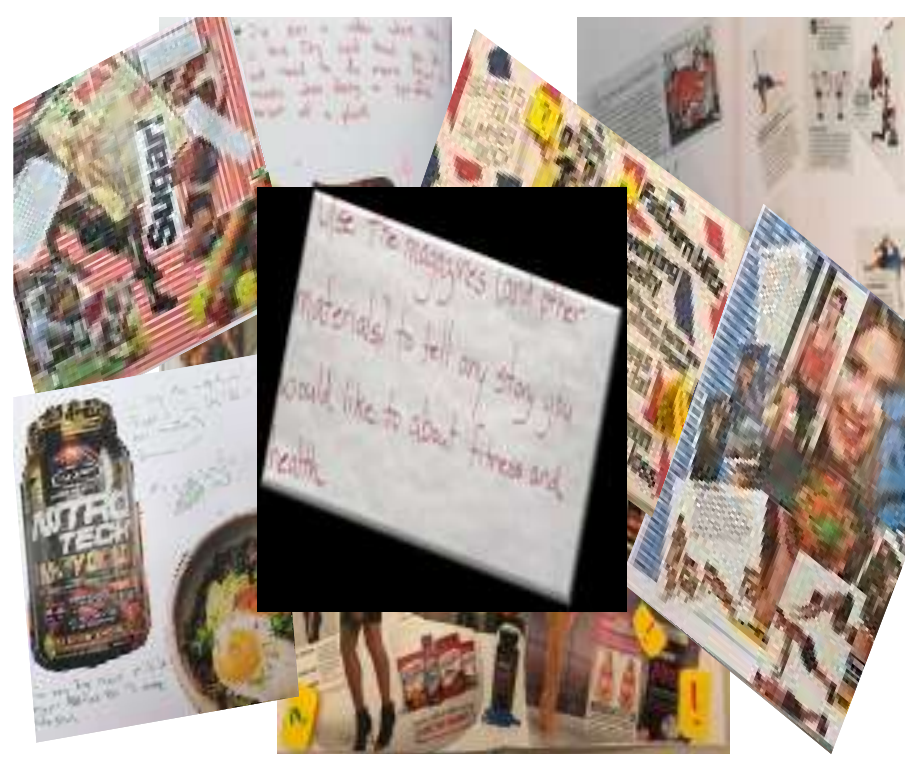

Figure 3. Magazine re-assemblages produced from week three of the scrapbooking project, focusing on health and fitness related magazines.

This process of using materials from magazines that were already professionally assembled through cultural and consumerist norms and then re-storying the materials with additional bodies (blank scrapbook pages, art supplies, conversation, text, drawing) created affective capacities, flows, and forces. These capacities, formulating (new) assemblages with each scissor snip or crumpling of paper, held potential to augment and/or limit different ways these youth (re-)presented health and fitness. With my own established educational and professional connections to health and fitness, the young participants responded to the material-discursive process in ways I did not (first) imagine. Sara re-acted to affective capacities of the magazines by producing little pop-up notes, layered on top of her magazine re-assemblage. These pop-up notes were folded pieces of bright yellow construction paper, covered with question marks and exclamation points on the outside and text inside - 'like seriously, her before is totally HEALTHY!' In this example, Sara's re-assembling responded to before-and-after photos from the magazines. She explicitly wanted to create something 'different' when she saw the 'same things over and over again.' She drew on her experiences as a young Latina to produce flows of affect that reterritorialized consumer images into a critique of normative body culture.

The magazine re-assembling process opened up conversations tied to popular culture, consumerism and gender, touching on topics from Kim Kardashian and cosmetic surgery to the financial, emotional costs of advertisements around pills, powders and supplements. I did not anticipate these lines of flight (Deleuze \& Guattari, 1987) and, in turn, these material-discursive moments produced flows of affect that altered my subjectivities and connections within the research assemblage. It also affected the ways in which I re-visited data from the third week of the scrapbooking project. While the magazine re- 
assembling 'began' with participants (and myself) producing re-assemblages (scrapbook collages), the affects lingered in my further re-searching. Affects produced capacities for me to continue to create (new) re-assemblages from our work. In other words, these flows of affect inspired me to take the reassemblages and re-assemble them by drawing on materials from each of our 'initial' magazine reassemblages. This re-assembling became a collage of materials, texts, thoughts and more, entangled in wonder (MacLure, 2013a), doubt (Holbrook \& Pourchier, 2014) and a slowness to work against established patterns towards something different (Hickey-Moody, 2013; Renold, 2018). In this iterative process of re-assembling, theory, methods and 'findings' became entangled.

\section{Wonder, doubt, slowness and a collage-in-process}

There was no particular 'order' in how the theoretical-methodological process of my inquiry came to be. I often 'begin' with wonder when re-visiting data through an affective lens. Referring back to MacLure (2013a), "Wonder is relational. It is not clear where it originates and to whom it belongs" (p. 229). For me, wonder becomes entangled with affect. So, while I was not necessarily aware of intensities produced through/by the data before - or even as it happened, in continual encounters with data from the magazine re-assembling, people, objects, images and fragments rejuvenated bodies' capacities to affect and be affected. In this wondering, affect produced the capacities to reimagine (and re-work) data from the participants' re-assemblages. I began to think-feel-write-sense my way through data in different ways. Affect took hold through a collaging process, filled with doubt (Holbrook \& Pourchier, 2014) and a recalibration towards slowness ('elbow room') (Renold, 2018) - as I struggled to open up practices not previously experienced.

I printed out hard copies of photos taken of the 'initial' magazine re-assemblages at the local pharmacy photo kiosk. I made multiple copies, in different formats and laid them out on the floor. I explored the artefacts horizontally, vertically, cropped and full size. I began to place the photos on an oversized white piece of foam core board - organized by participant, still grouped in a linear manner. Using collage as analysis, Holbrook and Pourchier (2014) wrote:

In organizing our materials, sometimes we methodically categorize-images with red go in one pile, objects with rust in another. Other times, we don't know why we select a piece as we work. Our hands dart out and clutch an artifact without voiced reason. We don't explain, we don't write words in our research diaries to justify our use. We just want it, and we feel delight in the urge to touch, grab, hold, manipulate. (p. 758).

As such, I reminded myself this placement of photos was temporary. I may have begun with organized groupings, but they did not have to remain that way. One potential of affect theorizing is the ability to pick up and leave off at different places (Ringrose et al., 2019). Here, the act of physically holding, 
moving and re-visiting the photos (re-assemblages) offered a "break" (Levy et al., 2016, p. 185) to research (and re-think) data. Through re-searching, the different bodies (my own, text from participants, images, memories) began to move back and forth between cutting, pasting, in-depth reading, notetaking, scribbling to see where this might lead and what affects these bodies might produce.

In collaging, I returned to the organized photo layout and began to play around with ideas, exploring the ways in which affective capacities may move in different directions. At times (especially in 'beginnings'), I was unsure how to 'let go' of my previous connections to a more systematic analysis. The creative, critical magazine re-assemblages the young participants produced through our scrapbooking were sacred. I did not want to undo or diminish their work. I stared at their creations incessantly, paralyzed at the idea of cutting (or manipulating) their re-assemblages. I was (and am) in awe of their contributions to the research.

I relished in the hesitancies. There are inherent power dynamics embedded in race, gender, age, culture that, even in a post-humanist inquiry, can be reified (Dernikos, Ferguson, \& Siegel, 2019). In fact, as I reflect on my own re-assembling, I most likely re-produced some of these territorializing flows of affect. As I 'look back' at these materials after leaving the field, I kept this with me, pausing (hesitating) to wonder what paths to 'take' (and not take) in order to resist re-inscribing "the structures of power/knowledge that privilege some ways of knowing/being over others" (Thorpe \& Marfell, 2019, p. 21). These hesitancies were embodied. For example, I tried to enable movement simply by cutting along the edges of some of the photos, moving them around on the floor, loosely placing them in various directions on the foam core board. Through these movements, I was territorialized and de-territorialized through the participants' subjectivities - something I would never be able to fully experience. This process was iterative and painstaking, but eventually led to the gluing down of participant generated artefacts to colored construction paper - just to initiate a 'start' to my re-assemblage of the collages.

In my hesitance, there were also openings. Entanglement with materiality produced possibilities for the inquiry to shoot off in multiple directions. Drawing from Holbrook and Pourchier (2014), I hoarded (or amassed) materials - transcripts, readings, colored pencils, research memos, images cut from and/or enlarged from the magazine re-assemblages. These were affective bodies that "glowed" (produced wonder) (MacLure, 2013a) when re-visiting the data. They included materials more directly attached to the magazine re-assembling (participants' scrapbooking, transcripts) along with those that found their way into the inquiry (scholarship, theory, popular culture references). For example, while the magazine re-assemblages acted as a focus of the inquiry, additional human and non-human bodies could not be excluded in the theoretical-methodological turn to affect. In these instances, I would take a (physical) pause from images to entwine other bodies that produced affect. This included re-reading participants' transcripts, pulling out words, comments and phrases that were entangled with the magazine reassemblages. This included scholarly readings (Hickey-Moody, 2013; Holbrook \& Pourchier, 2014; MacLure, 2013a; Renold, 2018), which enabled alternative pathways of inquiry. This included references 
from/to everyday physical culture, often connected to normative assumptions of the 'healthy' body (e.g., White, thin, toned, muscular, able, active), but tied to a questioning of how collaging might challenge and offer something different. This included reflections regarding myself and the young participants. All these bodies, stemming from different moments and points, were and/or became connected in the re-assembling. These relations amongst/between different bodies held the potential to produce affective flows that de-territorialized the normative research assemblage.

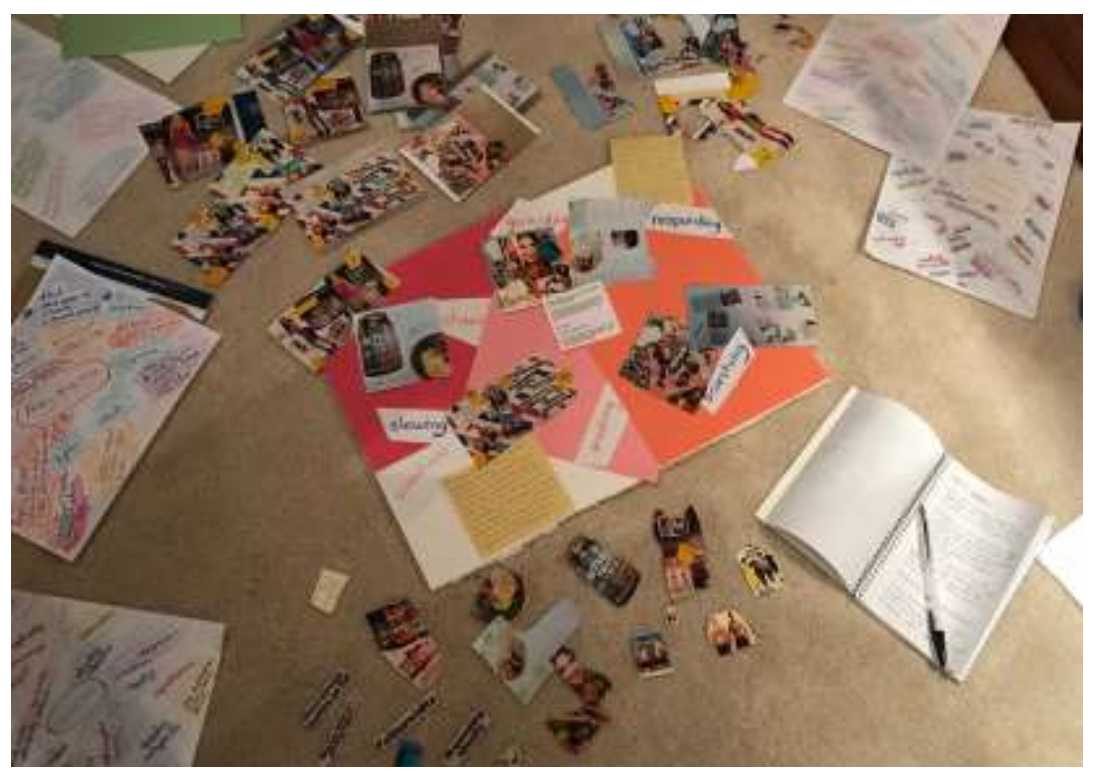

Figure 4. In collaging, relations between bodies produced affective capacities, augmenting and diminishing, pausing and extending possibilities at different points in the process.

Wonder, doubt, and questions around emerging relations between bodies produced pauses and continuations (figure 4). The incorporation of bodies (materials, human, culture, thoughts, writing, texts) became accompanied by unexpected processes. For instance, while literature (Hickey-Moody, 2013; Holbrook \& Pourchier, 2014; MacLure, 2013a; Renold, 2018) enabled me to think through theory, I did not want readings (and words) to take over the inquiry. I began to (re-)present readings by scribbling key words and phrases on blank pieces of paper. Then, in looking at them alongside images of the magazine re-assemblages, I was propelled to add color, underline and bold text to make these materials pop. Also, the initial hesitancy in cutting the hard copies of the photo initiated further movements through touching, cutting, taking apart and sorting. With each scissor snip of the health and fitness magazine reassemblages, different cuts and angles were produced; the materiality of this process brought snippets of conversations from the young participants into consideration. I recalled moments of wonder (discomfort, curiosity, fascination) (MacLure, 2013a) that the participants and I had engaged with through the magazine re-assembling. 
Lastly, it was no longer enough to touch, cut, sort, glue and layer materials in the collage. Flows of affect augmented and expanded the collaging process. At first, I created a power point, then added in audio and turned it into a video of the inquiry (https://vimeo.com/342140495). Affect, in this case, deterritorialized the two-dimensional re-assemblages and produced new flows of data enmeshed with audio-visual methods. Taking the photos, re-playing and re-watching the video offered another way to slow down and reimagine paths to illuminate (new) research and pedagogical practices for health and fitness. I had 'left' the field (after-school context), taken a pause from my initial (linear) approach, and returned to re-search data from an alternative (affective) angle. In this, I had begun to feel-senseimagine something different than what traditional qualitative approaches had provided me.

\section{(Re-)presenting bodies: what does this affective inquiry produce?}

The process of wondering, doubting and slowing through collage had, begun to produce affective capacities to move bodies somewhere different than before. It was still just beginning, and, in continuing to reimagine and (re-)present health and fitness through an affective lens, additional openings towards de-territorialization were produced. I briefly explore two of these openings - or 'findings' - next.

Re-considering subjectivities. Re-visiting the data through an affective lens (drawing on PhEmaterialism) provided an ethico-onto-epistemological stance to conceptualize all bodies (human, material, discursive) as important and interacting on one plane. PhEmaterialist concepts/tools (such as affect) work to reject the singular, humanist subject; instead, it is the relations of all things in the research assemblage that are taken into account (Ringrose et al., 2019). As such, re-visiting the health and fitness magazine reassemblages through an affective lens offered a much needed (and overdue) closeness with data from my dissertation. Through the closeness, I no longer had to act as the 'primary researcher' - a term I had been prodded to use (yet abhorred) in writing/representation. This traditional stance had put me at "arm's length" (MacLure, 2013b, p. 167), distanced the process in which I had become deeply ingrained. Importantly, through the closeness, 'I' no longer had to assume the all-knowing researcher position as "the single organizer of the knowledge production" (Ringrose et al., 2019, p. 11). I recognized myself (and subjectivities) as one meager element in the inquiry.

Troubling the humanist perspective, Lenz Taguchi (2019) suggested "human agents and matter are mutually constitutive of each other" (p. 31). In re-assembling, objects and images that made up the collaging produced their own affective power for change. So, while I acknowledge the difficulty and even impossibility in 'letting go' of my (human) influence (perhaps especially when it comes to race, culture, age, and experiences), an entanglement with human and non-human bodies produced affects to research the data in divergent ways. Through collaging, attention became fixated on parts (image cutouts, texts, participants' words and feelings) previously hidden or unnoticed (e.g., relations between consumerism, popular culture and obesity prevention). Furthermore, in 'taking' participants magazine 
re-assemblages and re-assembling them, I felt a response-ability (Barad, 2012) to further consider participants' subjectivities and re-search ways to include often invisible subjectivities (race, class, gender). This became possible through the multi-modal nature of re-assembling and collaging.

Expanding modalities. The material aesthetic collage process enabled affective capacities for me to seethink-feel differently. Touching, pulling apart, gluing, re-configuring materials from the participants brought conversations (and voices) to the forefront, especially as I re-played these alongside debates in health, fitness and physical culture (Fullagar, 2017; Markula, 2019; Thorpe \& Marfell, 2019). For example, the yellow pop-up notes (question marks, exclamation points) Sara attached to her reassemblage did not just act as a critique of the things encountered and 'popular' messages received through health and fitness magazines. The pop-up notes themselves were an entanglement of images, drawings, text and (human) reactions which, in tandem with other participants' magazine reassemblages and physical culture, produced (new) affects. In addition to critiquing normative societal assumptions of the physical body ('I don't like that we associate being healthy with being skinny'), Sara's re-assemblage questioned the starting point for such normative assumptions around body size, shape and weight ('I don't get the whole concept of plus size'). Moreover, as other bodies became entwined in the collage, the inquiry propelled further questions into which (and whose) bodies 'matter' in a society that perpetuates links between obesity policy, fitness, culture and economics (Fullagar, 2017).

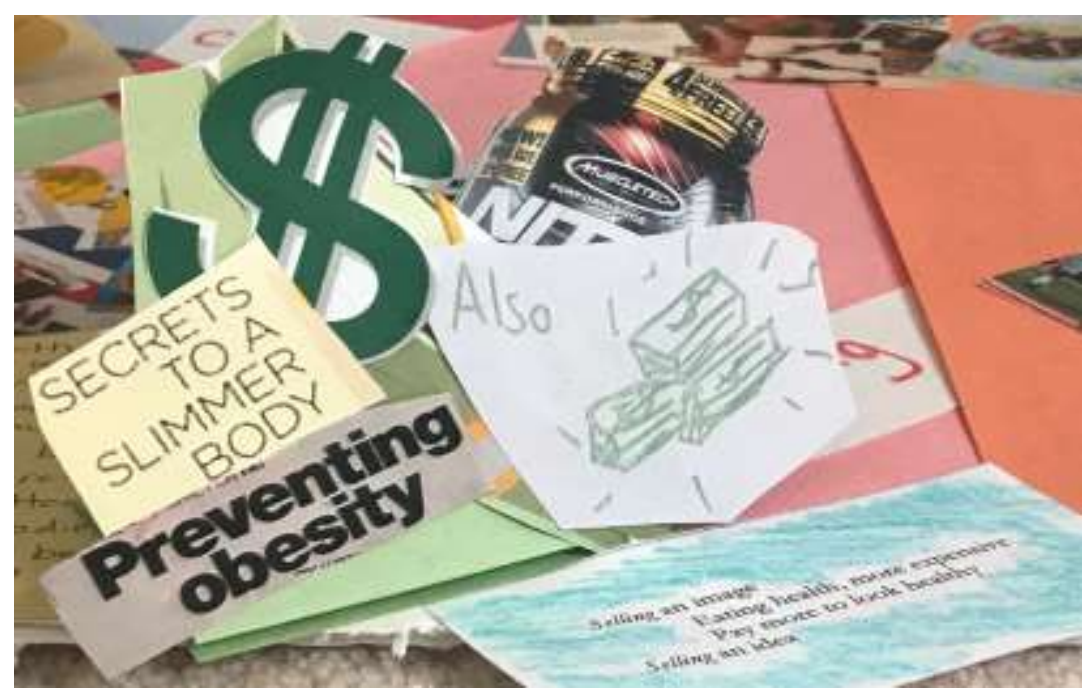

Figure 5. A cluster of materials re-assembled questions the consumerist aspect of obesity and to/for whom these aspects are accessible.

One point of the collage began to depict a cluster of materials related to money, obesity, slimness, and nutrition. This cluster stemmed from the magazine re-assemblages, some images expanded and layered with drawing and text (figure 5). The young participants were, indeed, aware of the high costs of 
'healthy' foods (fruits, vegetables) and nutritional supplements advertised by companies to attain a muscular physique. It was not lost on them that many of the lower socio-economic neighborhoods in which they (Black/Latinx youth) live are littered with Bodegas, offering cheaper, more processed foods. This cluster of materials, entangling consumerism (dollar bills), obesity prevention and physical status (implying there are 'secrets to a slimmer body') affected me to further consider the 'costs' (economic, physical, psychological, social, cultural) of normative health and fitness messages. It affected me to bring in materials from other weeks in the scrapbooking project (e.g., poetic transcription). Drawing on affective data, Niccolini (2016a) wrote, "words and images work interdependently, producing new forms and feelings in combination that exceed what either could elicit alone" (p. 235). This small cluster of materials augmented capacities to open up health and fitness stories through the participants' reassemblages and my re-assembling. It is just one example of what the affective inquiry began to produce.

\section{Reimagining research and practice through affect}

In 'ending' this paper, it is still just a beginning. More aptly, I am leaving off in what Deleuze and Guattari (1987) refer to as the middle. From a Deleuzian perspective, there are no beginnings or ends; assemblages (and affect) exist only in establishing connections between other bodies - and it is impossible to know where/how these start or finish. Instead, bodies are always becoming (print magazines transformed into participants' magazine re-assemblages, magazine re-assemblages entangled with texts, my subjectivities entwined with process). "The middle is by no means average; on the contrary, it is where things pick up speed" (Deleuze \& Guattari, 1987, p. 25). The middle, then, is perhaps what offers possibilities for human, material and discursive bodies to produce something new in relation to health and fitness research and practices (figure 6).

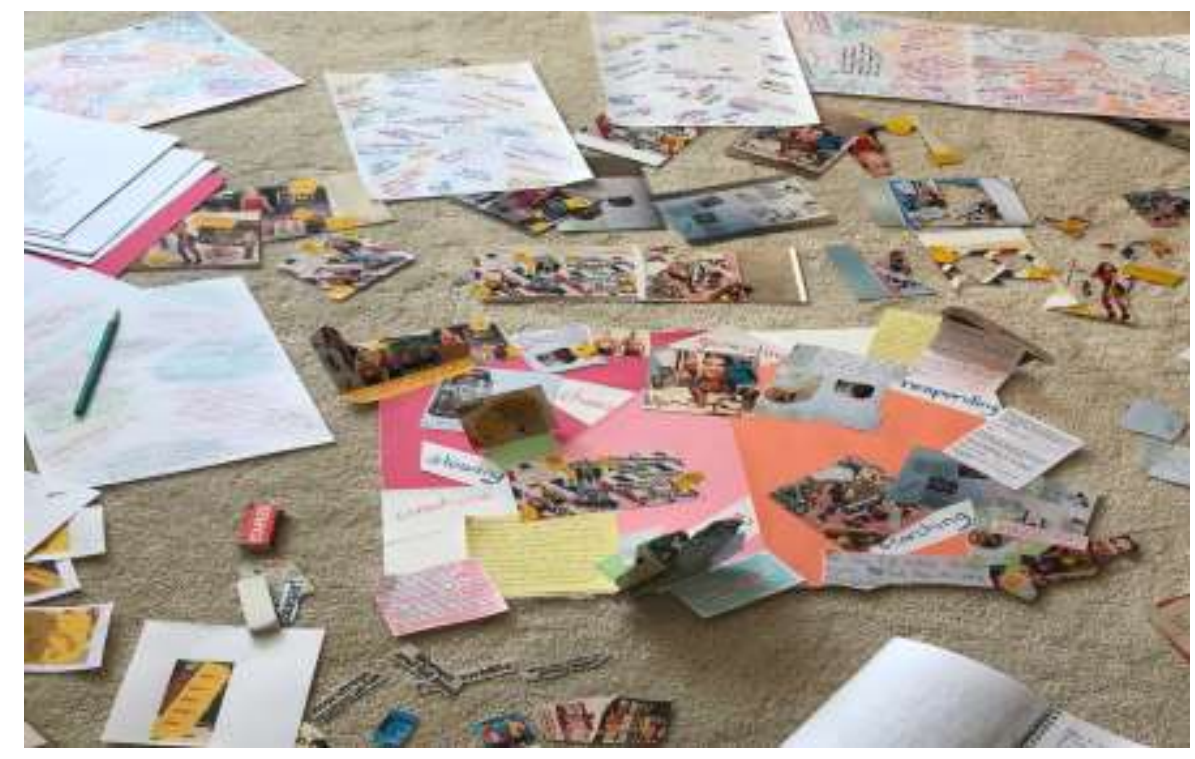

Reconceptualizing Educational Research Methodology 2019, 2,3(2) Special Issue https://journals.hioa.no/index.php/rerm/issue/view/397 
Figure 6. The middle of collaging includes materials glued onto the foam core board, dispersed on the floor and my own (physical) body walking, kneeling, sitting next to, laying down and standing over to access multiple perspectives.

Thinking-doing-feeling my way through collaging augmented and diminished affective capacities. It opened questions into my own subjectivities. I gained deeper appreciation for things (time, materials, thoughts, experiences) the participants shared and produced. In certain ways, the collage inquiry became an act of "response-ability" - "being responsible and responsive to the world's patternings and murmurings" (Barad, 2012, p. 207). For instance, my unexpected engagement in taking photos, creating a power point, embedding audio and then re-playing this, opened another way to wonder, doubt and slow 'usual' research practices. In developing and replaying a video montage of children's photographs, Luttrell and Clark (2018) employed response-ability to rethink methodological and ethical imperatives. They connect response-ability to a discovery process so researchers can "shift from a 'need to know more' to a 'need to explore more through making'" (ibid., p. 779). On the one hand, the making and exploring of collaging was an invitation to think, touch, feel, share and become part of the process (Renold, 2018). Response-ability was a reminder to not shut down inquiry because of discomfort, excitement, or the unknown. In other ways, I was keenly aware of the limits to my response-ability. For one, this re-visiting of data from the magazine re-assemblages took place after I had 'left' the afterschool context. I was no longer engaging with the participants regularly. Also, as a White able-bodied female (from a privileged suburban upbringing), there are undeniable affects (race, gender, culture, experience, age) produced by my body in the research assemblage. In addressing response-ability, I can only recognize this inquiry as partial, contextual and interconnected, consisting of the bodies that make up the re-assemblage at any given point. Referring back to Barad (2012), I think-work-write through this 'experiment' "without any illusion of clean hands" (p. 207). There are always bodies rendered invisible by privileging some over others. Thus, one of (many) questions I am left with in respect to the collaging is how this helps reimagine what 'matters' for educational research, pedagogical and political practices in health and fitness?

With this, I lastly consider what an affective lens might do for health/fitness research and practices with Black/Latinx youth. Again, there is a long history of privileging certain bodies (White, heterosexual, ablebodied, fit) over others (Black/Brown, queer, disabled, fat) in PE, health, fitness and physical culture (Dagkas, 2014; Fitzpatrick, 2013; Fullagar \& Pavlidis, 2018; Landi, 2018). This privileging may be more problematic as the current educational and political climate (in the U.S.) prioritizes corporatization, individualism and privatization (Strom \& Martin, 2017), which further marginalize (and assault) Black/Latinx bodies (Dernikos et al., 2019). With physical culture (through PE, sports, media, after-school programming) inevitably tied to sociopolitical issues (Fullagar, 2017) and scholarship embedded in commercial networks of connection (Gard \& Pluim, 2017), I can't help but emphasize ways to do research and educational practices differently. In this, my turn to affect and experiment into collaging 
began to offer one possibility to reimagine such practices. Traditional education and research in PE, health and fitness have often taken the position that health and fitness are static constructs (Wright \& Burrows, 2004). Definitive outcomes (e.g., body composition, aerobic capacity) are prioritized, linking increased knowledge to improved changes in health behaviors. This emphasis on outcomes over process, however, problematically narrows research agendas and pedagogical practices (Gard \& Pluim, 2017). I draw from others (Fitzpatrick, 2018; Fullagar, 2017) whom acknowledge the importance of critical work to challenge normativity and mobilize different perspectives in PE and physical culture. As such, the 'experiment' (paper) and collage offers no 'final' answers. Instead, it is my hope for it to open up multiple, unpredictable pathways that reimagine health and fitness research and practices. Holbrook and Pourchier (2014) wrote:

Because our collages are exposures and not answers, they are always one of manymultiple and ongoing as long as we continue to inquire. (p. 761).

Thus, returning to my confession, I do not have clear answers for what this 'experiment' did (and what it may continue to do as I add on, take away, or shift materials). Yet, as affects picked up and intensified at various points, it produced possibilities to re-visit and re-think differently through all bodies. Notably, in this case, it was the production of materials from four Black and Latinx youth that even allowed me to envision something new.

\section{References}

Allen, L. (2011). Young people and sexuality education: Rethinking key debates. New York: Palgrave Macmillan. https://doi.org/10.1057/9780230297630

Azzarito, L. (2009). The Panopticon of physical education: pretty, active and ideally white. Physical Education \& Sport Pedagogy, 14(1), 19-39. https://doi.org/10.1080/17408980701712106

Barad, K. (2012). On touching - The inhuman that therefore I am. Differences: A Journal of Feminist Cultural Studies, 23(3), 206-223. https://doi.org/10.1215/10407391-1892943

Bogdan, R., \& Biklen, S. (2007). Qualitative research for education: An introduction to theories. Qualitative research for education: An introduction to theories (5th ed.). Boston: Allyn and Bacon.

Bragg, S., \& Buckingham, D. (2008). "Scrapbooks" as a resource in media research with young people. In P. Thomson (Ed.), Doing visual research with children and young people (pp. 114-131). London: Routledge.

Coffey, J. (2017). Aestheticized bodies. In M. L. Silk, D. L. Andrews, \& H. Thorpe (Eds.), Routledge handbook of physical cultural studies. London: Routledge. https://doi.org/10.4324/9781315745664-23

Creswell, J. W. (2013). Qualitative inquiry \& research design: Choosing among five approaches (3rd ed.). Thousand Oaks, CA: Sage.

Dagkas, S. (2014). Who has health problems? Class, racialization and health. In K. Fitzpatrick \& R. Tinning (Eds.), Health education: Critical perspectives (pp. 93-104). London: Routledge. 
Deleuze, G., \& Guattari, F. (1987). A thousand plateaus: Capitalism and schizophrenia. Minneapolis: University of Minnesota Press.

Dernikos, B. P., Ferguson, D. E., \& Siegel, M. (2019). The possibilities for "humanizing" posthumanist inquiries: an intra-active conversation. Cultural Studies - Critical Methodologies, 1-14. https://doi.org/10.1177/1532708619829793 https://doi.org/10.1177/1532708619829793

Emerson, R. ., Fretz, R. ., \& Shaw, L. . (2011). Writing ethnographic fieldnotes (2nd ed.). Chicago: The University of Chicago Press. https://doi.org/10.7208/chicago/9780226206868.001.0001

Enright, E., \& O'Sullivan, M. (2013). “Now, I'm Magazine Detective the Whole Time": Listening and Responding to Young People's Complex Experiences of Popular Physical Culture. Journal of Teaching in Physical Education, 32(4), 394-418. https://doi.org/10.1123/jtpe.32.4.394

Fitzpatrick, K. (2013). Critical pedagogy, physical education and urban schooling. New York, NY: Peter Lang.

Fitzpatrick, K. (2018). What happened to critical pedagogy in physical education? An analysis of key critical work in the field. European Physical Education Review, 1-18. https://doi.org/10.1177/1356336X18796530

Fox, N. J., \& Alldred, P. (2017). Sociology and the new materialism. London: Sage. https://doi.org/10.4135/9781526401915

Fullagar, S. (2017). Post-qualitative inquiry and the new materialist turn: implications for sport, health and physical culture research. Qualitative Research in Sport, Exercise and Health, 9(2), 247-257. https://doi.org/10.1080/2159676X.2016.1273896

Fullagar, S., \& Pavlidis, A. (2018). Feminist theories of emotion and affect in sport. In L. Mansfield, J. Caudwell, B. Wheaton, \& B. Waston (Eds.), The Palgrave handbook of feminism and sport, leisure and physical education (pp. 447-462). London: Palgrave Macmillan. https://doi.org/10.1057/9781-137-53318-0_28

Gard, M., \& Pluim, C. (2017). Why is there so little critical physical education scholarship in the United States? The case of Fitnessgram. Sport, Education and Society, 22(5), 602-617. https://doi.org/10.1080/13573322.2016.1213716

Hickey-Moody, A. (2013). Affect as Method: Feelings, Aesthetics and Affective Pedagogy. In R. Coleman \& J. Ringrose (Eds.), Deleuze and Research Methodologies (pp. 79-95). Edinburgh, UK: Edinburgh University Press.

Holbrook, T., \& Pourchier, N. M. (2014). Collage as Analysis : Remixing in the Crisis of Doubt. Qualitative Inquiry, 20(6), 754-763. https://doi.org/10.1177/1077800414530260

Johns, D. P., \& Tinning, R. (2006). Risk reduction: Recontexualizing health as a physical education curriculum. Quest, 58(4), 395-409. https://doi.org/10.1080/00336297.2006.10491890

Landi, D. (2018). Toward a queer inclusive physical education. Physical Education and Sport Pedagogy, 23(1), 1-15. https://doi.org/10.1080/17408989.2017.1341478

Landi, D. (2019). Queer men, affect, and physical education. Qualitative Research in Sport, Exercise and Health, 11(2), 168-187. https://doi.org/10.1080/2159676X.2018.1504230

Lenz Taguchi, H. (2019). Images of thinking in feminist materialisms: ontological divergences and the production of researcher subjectivities. In J. Ringrose, K. Warfield, \& S. Zarabadi (Eds.), Feminist posthumanisms, new materialisms and education (pp. 25-35). London: Routledge.

Levy, G., Halse, C., \& Wright, J. (2016). Down the methodological rabbit hole: thinking diffractively with resistant data. Qualitative Research, 16(2), 183-197. https://doi.org/10.1177/1468794115571434

Lupton, D. (2018). "Better understanding about what's going on": Young Australians' use of digital 
technologies for health and fitness. Sport, Education and Society.

https://doi.org/10.1080/13573322.2018.1555661

Luttrell, W., \& Clark, E. (2018). Replaying our process: Video/art making and research. Qualitative Inquiry, 24(10), 775-785. https://doi.org/10.1177/1077800418800106

MacLure, M. (2013a). The wonder of data. Cultural Studies - Critical Methodologies, 13(4), 228-232. https://doi.org/10.1177/1532708613487863

MacLure, M. (2013b). Classification or Wonder? Coding as an Analytic Practice in Qualitative Research. In R. Coleman \& J. Ringrose (Eds.), Deleuze and Research Methodologies (pp. 164-183). Edinburgh, UK: Edinburgh University Press.

Markula, P. (2008). Affect[ing] bodies: performative pedagogy of pilates. International Review of Qualitative Research, 1(3), 381-408.

Markula, P. (2019). What is new About new materialism for sport sociology? Reflections on body, movement, and culture. Sociology of Sport Journal, 36, 1-11. https://doi.org/10.1123/ssj.20180064

Niccolini, A. (2016a). Animate affects: censorship, reckless pedagogies, and beautiful feelings. Gender and Education, 28(2), 230-249. https://doi.org/10.1080/09540253.2015.1121205

Niccolini, A. D. (2016b). Uneasy subjects: Affect, censorship, schooling. Columbia University.

Niccolini, A. D., Zarabadi, S., \& Ringrose, J. (2018). Spinning yarns: Affective kinshipping as posthuman pedagogy. Parallax, 24(3), 324-343.

Pink, S. (2013). Doing visual ethnography (3rd ed.). London: Sage.

Pringle, R. (2007). Sport, males and masculinities. In C. Collins \& S. Jackson (Eds.), Sport in Aotearoa/New Zealand Society (pp. 355-380). Melbourne, Australia: Thomson.

Renold, E. (2018). 'Feel what I feel': Making da(r)ta with teen girls for creative activisms on how sexual violence matters. Journal of Gender Studies, 27(1), 37-55. https://doi.org/10.1080/09589236.2017.1296352

Ringrose, J., \& Renold, E. (2014). “F**k Rape!” Qualitative Inquiry, 20(6), 772-780. https://doi.org/10.1177/1077800414530261

Ringrose, J., Warfield, K., \& Zarabadi, S. (2019). Introducing feminist posthumanisms/new materialisms \& educational research: Response-able theory-practice-methodology. In Feminist posthumanisms, new materialisms and education (pp. 1-15). London: Routledge.

Safron, C. (2019). Health, fitness, and affects in an urban after-school program. Sport, Education and Society. https://doi.org/10.1080/13573322.2019.1625318

Seigworth, G. J., \& Gregg, M. (2010). Introduction: An Inventory of Shimmers. In M. Gregg \& G. J. Seigworth (Eds.), The affect theory reader (pp. 1-28). Durham, NC: Duke University Press.

St. Pierre, E., \& Jackson, A. Y. (2014). Qualitative data analysis after coding. Qualitative Inquiry, 20(6), 715-719. https://doi.org/10.1177/1077800414532435

Strom, K. J. (2015). Teaching as assemblage : Negotiating learning and practice in the first year of teaching. Journal of Teacher Education, 66(4), 321-333. https://doi.org/10.1177/0022487115589990

Strom, K. J., \& Martin, A. D. (2017). Thinking with theory in an era of Trump. Issues in Teacher Education, 26(3), 22.

Theberge, N. (1981). A critique of critiques: Radical feminist writings on sport. Social Forces, 60, 341353. https://doi.org/10.2307/2578439

Thorpe, H., \& Marfell, A. (2019). Feminism and the physical cultural studies assemblage: revisiting 
debates and imagining new directions. Leisure Sciences, 41(1-2), 17-35. https://doi.org/10.1080/01490400.2018.1539684

Tinning, R., \& Fitzpatrick, K. (2012). Thinking about research frameworks: Richard Tinning and Katie Fitzpatrick. In K. Armour \& D. Macdonald (Eds.), Research methods in physical education and youth sport (1st ed., pp. 45-53). London: Routledge.

Tinning, Richard. (2010). Pedagogy and human movement: Theory, practice, research. London: Routledge. https://doi.org/10.4324/9780203885499

Wright, J., \& Burrows, L. (2004). "Being Healthy": The discursive construction of health in New Zealand children's responses to the national education monitoring project. Discourse: Studies in the Cultural Politics of Education, 25(2), 211-230. https://doi.org/10.1080/01596300410001692157 